\title{
Visual Outcome And Complications of Manual Sutureless Small Incision Cataract Surgery-A Rural Hospital Based Study
}

\author{
${ }^{1}$ Dr. P. Tidake Asso, ${ }^{2}$ Dr P. Madan \\ Prof. Jnmc Sawangi Wardha ${ }^{1,}$ Pg Student Jnmc Sawangi Wardha ${ }^{2}$
}

\begin{abstract}
:
Introduction: According to World Health Organization, an estimated 20 million people are blind from bilateral cataracts and this growing backlog poses one of the greatest public health challenges for $21^{\text {st }}$ century.

Materials And Method: it was a randomized prospective study with a sample size of 200 eyes of 200 patients. It was conducted for 1 year. Patients were explained about the study and those willing to participate in the study were included in the study. After taking the consent of patient all patients were examined.

RESULTS-58.5\% cases were male and $41.5 \%$ were females. Mean age was 66 years. Mean axial length was $22.64 \pm 0.86$. Post-operative under corrected visual acuity was $6 / 18$ or better in $81 \%$ eyes at 1 week and $92.5 \%$ eyes at 4 week respectively and 6/12 or better in $68 \%$ of eyes at 12 weeks. Post-operative VA with pin hole was $6 / 12$ or better in $87 \%$ eyes at 1 week and 191(95.5\%) eyes at 4 week and $97 \%$ of eyes at 12-weeks respectively. .92. $46 \%$ patients having against the rule astigmatism with mean value of $88.24 \pm 7.37$. 54\% patients achieved BSCVA of 6/6 and $30.5 \%$ patients having BSCVA of 6/9.

Summary And Conclusion: Cataract is still the leading cause of avoidable blindness in the developing world. Unless cataract surgery rates were increased, the magnitude of cataract blindness will continue to increase. Early rehabilitation of the patients and no suture-related problems are main advantages of this technique. Manual sutureless small incision cataract surgery(MSICS) is a safe and effective technique for cataract surgery, especially in developing world.
\end{abstract}

\section{Introduction}

Cataract is the leading cause of avoidable blindness worldwide, accounting for nearly half (47.8\%) of all cases of blindness. According to World Health Organization, an estimated 20 million people are blind from bilateral cataracts and this growing backlog poses one of the greatest public health challenges for $21^{\text {st }}$ century. The cataract surgical rate (CSR) is an important public health metric, which represents the number of cataract operations annually performed per 1 million of population. There was significant variations in the CSR among different countries.

There is clearly a pressing need in the developing world to reduce the backlog of cataract blindness by increasing the CSR over current low rates. Finally, the advanced mature cataracts and brunescent hard cataracts that are so prevalent among poor populations are more challenging to extract with phaco, and the complication rate is higher in most hands except in most skilled and experienced phaco surgeons. Because of these problems associated with phaco in developing world, alternative techniques such as sutureless manual small incision cataract surgery (MSICS) are gaining popularity.

Manual sutureless small incision cataract surgery (SICS) has been proved to be an equally effective and a highly cost- effective alternative to instrumental phaco with a low complication rate. It is generally noticed that the incidence of postoperative astigmatism is more anterior the incision the greater the induced astigmatism. The overall safety profile of MSICS was found to be excellent with intra and postoperative complication rates comparable to phacoemulsification and ECCE. Multiple studies reported the safety and efficacy of MSICS for complicated cases, such as brunescent and white cataract and cataracts associated with phacolytic and phacomorphic glaucoma. Compared to phacoemulsification, MSICS was associated with lower and shorter operative times. Visual outcomes were excellent and comparable to phacoemulsification with upto 6 months follow up.

\section{Aims And Objective}

1. To determine the surgically induced astigmatism.

2. To determine complications of manual sutureless small incision cataract surgery.

3. To asses final best spectacle corrected visual acuity at 3 months. 


\section{Materials And Method}

Study Design: Randomized prospective study conducted in dept. of ophthalmology, Acharya Bhave Rural Hospital (AVBRH), Sawangi, Meghe, Wardha,Maharashtra. Sample size of study was 200 eyes of 200 patients. It was conducted for 1 year.

Inclusion Criteria-

1. Immature Senile Cataract.

2. Mature Senile Cataract.

\section{Exclusion Criteria-}

1. Posterior segment pathologies

2. Glaucoma, uveitis, trauma, dry eye.

3. Corneal opacity significantly affecting vision.

4. Developmental cataract.

5. Nuclear sclerosis more than grade 4.

6. Primary PCO.

7. Patients with irregular follow-up.

\section{Pre-operative examination consisted of-}

1. Visual acuity

2. Detailed slit lamp examination to rule out any significant anterior segment pathologies.

3. Type of cataract on the basis of morphology on slit lamp.

4. Applanation tonometry

5. A scan was done by contact method

6. Keratometry was carried out with Topcon auto keratometer of all cases.

7. Fundus examination was done to rule out any posterior segment pathologies.

\section{At all follow-up visit i.e.at (1week, 4weeks \& 12weeks)-}

1. Visual acuity

2. Detailed slit lamp examination for any post-op surgical complication.

3. Keratometer was done for type and amount of astigmatism

4. Auto refractometry was done.

5. Fundus examination was done.

At last follow up along with above all, refraction was given and axis of astigmatism along with best spectacle visual acuity was recorded. Any complications found during surgery or on follow up visits were also recorded. All reading were taken by single observer to obtain consistent results.

Astigmatism was recorded in dioptres. Astigmatism was graded and classified according to-

\section{Holmstrom's}

Gradation As,

- No astigmatism, when it was $<0.25 \mathrm{D}$

- Non- significant, when it was $>=0.25 \mathrm{D}$ but $<1.0 \mathrm{D}$

- Significant, when it was $>=1.0 \mathrm{D}$ but $<2.0 \mathrm{D}$

- High, when it was $>=2.0 \mathrm{D}$

The axes of astigmatism were divided into three classes-

- "With the rule " (minus cyclinder at 180 degree \pm 15 degree)

- "Against the rule" (minus cyclinder at $90 \mathrm{~d} \pm 15 \mathrm{~d}$ ) and

- "oblique" (minus cylinder at 16d - 74d \& 106d - 164 d )

All the surgeries were performed in operation theatre of Acharya Vinoba Bhave Rural Hospital by Extracapsular cataract extraction with posterior chamber intraocular lens implantation by manual sutureless small incision cataract surgery.

Preoperative- consent taken.

- Xylocaine Sensitivity Testing was done.

- Inj. TT0.5 ml I.M. was given to every patient.

- Anaesthesia used (local anaesthesia)- Xylocaine 2\% with adrenaline 1:100000 (peribulbar block) 


\section{Steps of surgery:}

1. The eye and peri-ocular skin was properly disinfected by painting with povidine iodine solution. Draping was done. Universal speculum was applied.

2. After conjunctival section, gentle cautery was done to stop any bleed. Frown incision was given at a distane of $2 \mathrm{~mm}$ from limbus, with a 15 number blade.

3. The external width of the incision was made of $6-8 \mathrm{~mm}$ according to the expected size of nucleus.

4. Sclero- corneal incision was made with a crescent knife and entry into the anterior chamber with a $3.2 \mathrm{~mm}$ keratome.

5. The internal opening of the incision was wider, so as to facilitate the nucleus delivery. Before entering into the $\mathrm{AC}$, a side port was made at the limbus, at right angle to the plane of approach with the $1.2 \mathrm{~mm}$ lance tip.

6. Anterior chamber was filled with visco-elastic sunstance by injecting it through side port.

7. Anterior capsulotomy was done with help of a self - made cystitome and capsulorhexis forcep.

8. Hydrodissection and hydrodelination was performed in almost all cases and nucleus was delivered either by hydro-expression or by visco-expression.

9. Cortical matter was aspirated with Simcoe's cannula and a rigid single-piece poly methyl methacrylate (PMMA) IOL was implanted within the bag or in the ciliary sulcus.

10. Visco - elastic material was removed.

11. Scleral wound was then checked for its self sealing character and conjunctiva approximated by closing with gentle cautery.

12. Subconjunctival Inj. Gentamycin and Dexamethasone was given.

13. Chlopamphenicol eyeointment was applied.

14. Pad \& bandage was done.

\section{Observations And Results-}

Out of 200 cases, $117(58.5 \%)$ cases were male and $83(41.5 \%)$ were females with mean age of 66 years. Age and gender wise distribution is

Table 1 - Age wise and gender wise distribution of patients.

\begin{tabular}{|l|l|l|l|}
\hline Age groups (years) & Male & Female & Total \\
\hline $\mathbf{5 0 - 5 9}$ & $11(5.5 \%)$ & $9(4.5 \%)$ & $20(10 \%)$ \\
\hline $\mathbf{6 0 - 6 9}$ & $56(28 \%)$ & $55(27.5 \%)$ & $111(55.5 \%)$ \\
\hline $\mathbf{7 0 - 7 9}$ & $41(20.5 \%)$ & $18(9 \%)$ & $59(29.5 \%)$ \\
\hline $\mathbf{8 0 - 8 9}$ & $9(4.5 \%)$ & $1(0.5 \%)$ & $10(5 \%)$ \\
\hline Total & $117(58.5 \%)$ & $89(41.5 \%)$ & $200(100 \%)$ \\
\hline
\end{tabular}

Table 2 - 105 patients whose RE was operated and 95 patients LE was operated.

\begin{tabular}{|l|l|l|}
\hline Eye & RE & LE \\
\hline No. Of patients & 105 & 95 \\
\hline
\end{tabular}

Mean axial length was $22.64 \pm 0.86$

Table 3: Distribution of patients according to axial length

\begin{tabular}{|l|l|l|}
\hline Axial length & No. Of patients & Percentage (\%) \\
\hline$<=21.99 ~ \mathbf{~ m m}$ & 35 & 17.5 \\
\hline $\mathbf{2 2 - 2 4 m m}$ & 154 & 77.0 \\
\hline$>=\mathbf{2 4 . 0 1} \mathbf{~ m m}$ & 11 & 5.5 \\
\hline Total & 200 & 100 \\
\hline
\end{tabular}

$1^{\text {st }}$ follow-up 4 weeks post-op. $2^{\text {nd }}$ follow up 4 weeks post op. Last follow-up 12 weeks post.op. Post-operative under corrected visual acuity was $6 / 18$ or better in $162(81 \%)$ eyes at 1 week and $185(92.5 \%)$ eyes at 4 week respectively and 6/12 or better in 136(68\%) of eyes at 12 weeks.

Table4- Distribution of patients according to unaided visual acuity.

\begin{tabular}{|l|l|l|l|l|l|l|l|}
\hline & $\begin{array}{l}\text { No. Of eyes } \\
\text { examined }\end{array}$ & $\mathbf{> 6 / 9}$ & $\mathbf{6 / 1 2}$ & $\mathbf{6 / 1 8}$ & $\mathbf{6 / 2 4 - 6 / 6 0}$ & $\begin{array}{l}>\mathbf{6 / 6 0} \\
\text { or }<\text { HM }\end{array}$ & $\begin{array}{l}\text { >HM- } \\
\text { PL }\end{array}$ \\
\hline Pre op & 200 & 0 & 0 & 0 & 45 & 137 & 17 \\
\hline $\mathbf{1}^{\text {st follow up }}$ & 200 & 0 & 47 & 115 & 38 & 0 & 0 \\
\hline $\mathbf{2}^{\text {nd }}$ follow up & 200 & 7 & 81 & 98 & 14 & 0 & 0 \\
\hline Last follow up & 200 & 32 & 104 & 57 & 7 & 0 & 0 \\
\hline
\end{tabular}

Graph1 : Distribution of patients according to unaided visual acuity. 


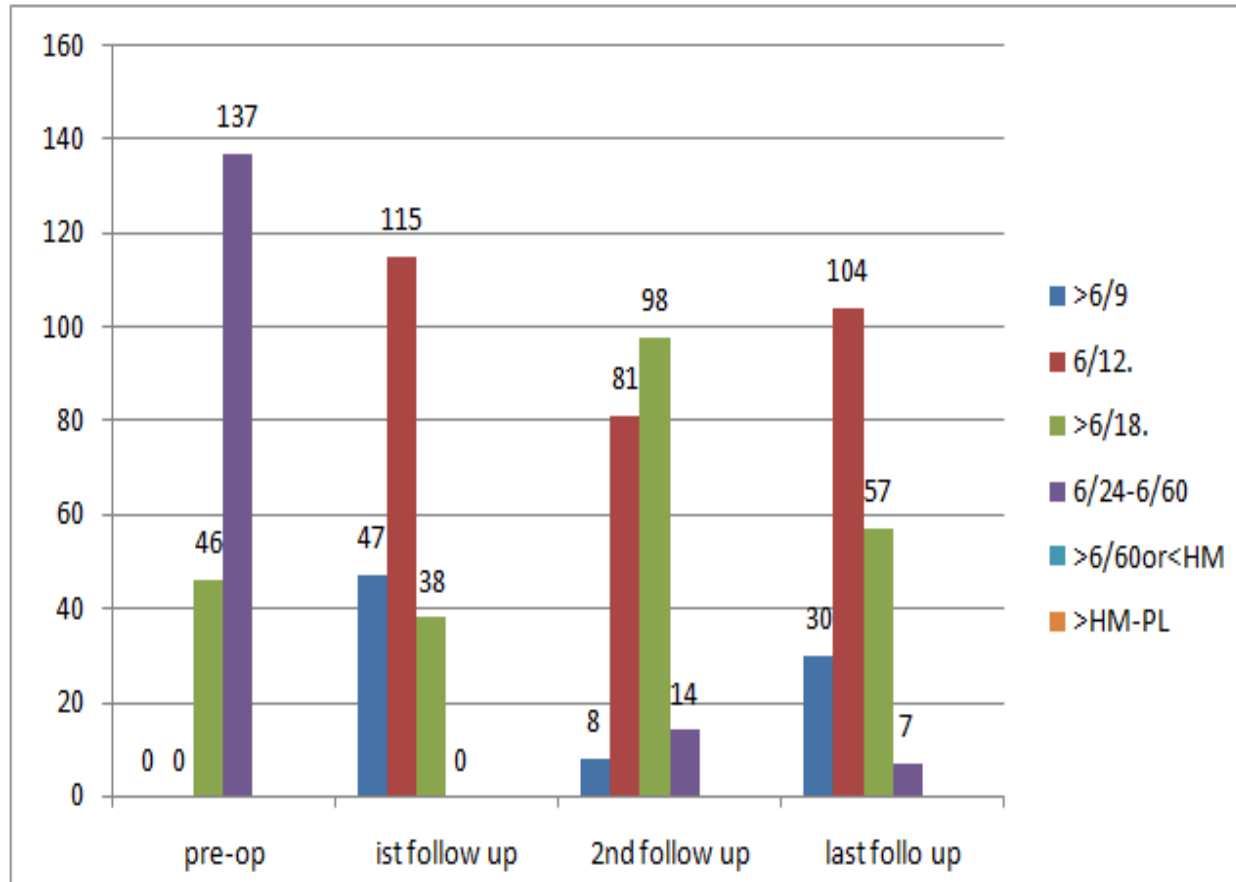

$1^{\text {st }}$ follow up- 4 weeks post op. $2^{\text {nd }}$ follow up 4 weeks post op. Last follow up 12 weeks post op. Post operative VA with pin hole was 6/12 or better in 174(87\%) eyes at 1 week and 191(95.5\%) eyes at 4 week and $194(97 \%)$ of eyes at 12 -weeks respectively.

Table 5: Distribution of patients according to visual acuity with pin hole.

\begin{tabular}{|l|l|l|l|l|l|l|l|}
\hline & $\begin{array}{l}\text { No. Of eyes } \\
\text { examined }\end{array}$ & $\mathbf{> 6 / 9}$ & $\mathbf{6 / 1 2}$ & $\mathbf{6 / 1 8}$ & $\mathbf{6 / 2 4 - 6 / 6 0}$ & $\begin{array}{l}>\mathbf{6} / \mathbf{6 0} \text { or } \\
<\text { HM }\end{array}$ & $\begin{array}{l}\text { >HM- } \\
\text { PL }\end{array}$ \\
\hline $\mathbf{1}^{\text {st }}$ follow up & 200 & 81 & 93 & 26 & 0 & 0 & 0 \\
\hline $\mathbf{2}^{\text {nd }}$ follow up & 200 & 116 & 75 & 9 & 0 & 0 & 0 \\
\hline $\mathbf{3}^{\text {rd }}$ follow up & 200 & 161 & 33 & 6 & 0 & 0 & 0 \\
\hline
\end{tabular}

Graph 2: Distribution of patients according to visual acuity with pin hole.

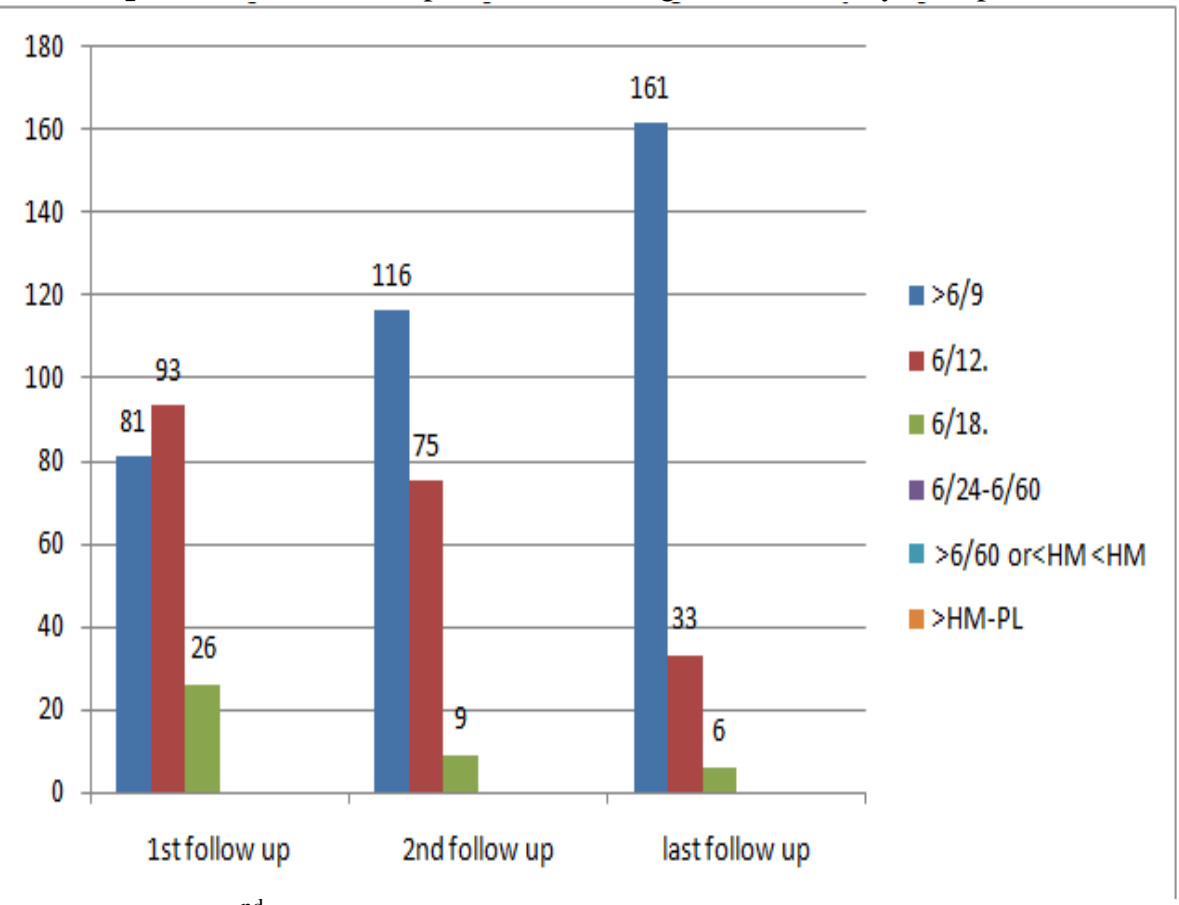

$1^{\text {st }}$ follow up 4 weeks post op. $2^{\text {nd }}$ follow up 4 weeks post op. Last follow up 12 weeks post op. 
Table 6 shows descriptive statistics for $\mathrm{k} 1$ and $\mathrm{k} 2$.

Pre-op K1 was $45.31 \pm 1.69$ and K2 was $44.64 \pm 1.63$

On $1^{\text {st }}$ follow up K1 was $45.54 \pm 1.82$ and $\mathrm{K} 2$ was $44.73 \pm 1.77$

On $2^{\text {nd }}$ follow up K1 was $45.54 \pm 1.82$ and $\mathrm{K} 2$ was $44.73 \pm 1.78$

Last follow up $\mathrm{K} 1$ was $45.53 \pm 1.81$ and $\mathrm{K} 2$ was $44.80 \pm 1.77$

Table 6: Descriptive statistics for K1 (Horizontal Corneal Curvature) and K2 (Vertical Corneal Curvature)

\begin{tabular}{|l|l|l|l|l|}
\hline & K1 & K2 & Z-value & p-value \\
\hline Pre-op & $45.31 \pm 1.69$ & $44.64 \pm 1.63$ & 8.172 & 0.0005 \\
& & & & $\mathrm{p}<0.05$ \\
\hline $\mathbf{1}^{\text {st }}$ follow up & $45.54 \pm 1.83$ & $44.73 \pm 1.77$ & 6.444 & $0.000 \mathrm{~S}$ \\
& & & & $\mathrm{P}<0.05$ \\
\hline $\mathbf{2}^{\text {nd }}$ follow up & $45.54 \pm 1.82$ & $44.73 \pm 1.78$ & 6.539 & 0.0005 \\
& & & & $\mathrm{P}<0.05$ \\
\hline Last follow up & $45.53 \pm 1.81$ & $44.80 \pm 1.77$ & 6.279 & 0.0005 \\
& & & & $\mathrm{P}<0.05$ \\
\hline
\end{tabular}

Graph3: Descriptive statistics for K1 (Horizontal corneal curvature) and K2 (Vertical corneal curvature)

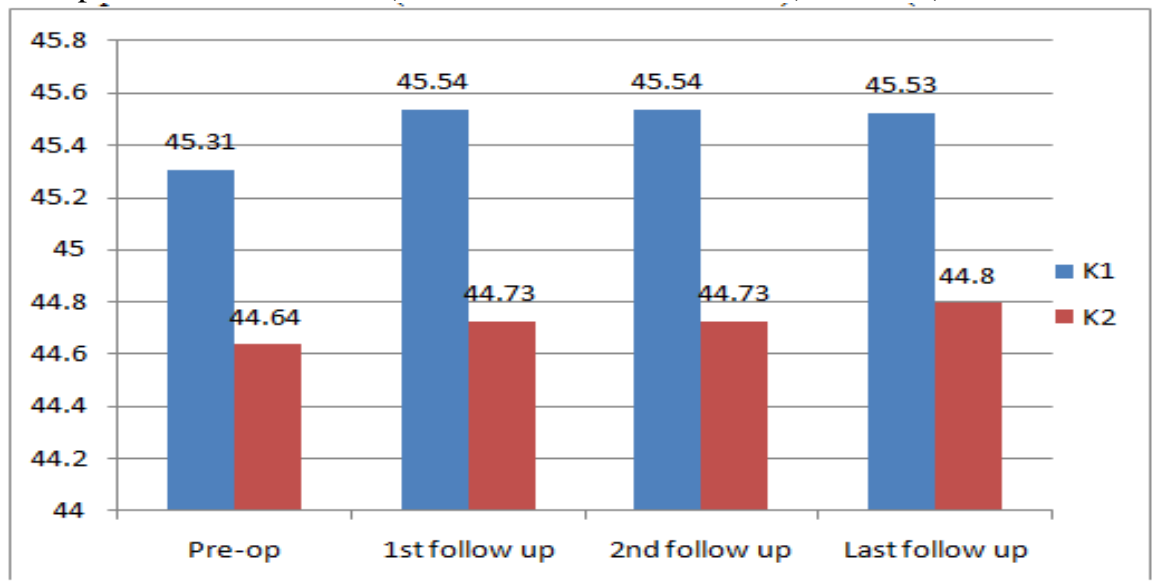

In our study, the average astigmatic dioptric difference was 1.05 preoperatively, 1.67 on first follow up and 1.65 on second follow up which was reduced to 1052 on last follow up suggesting that the difference was statistically significant $(\mathrm{P}<0.0001)$

Table7 : Distribution of patients according to Astigmatism in Diopters

\begin{tabular}{|l|l|l|l|l|l|}
\hline & $\begin{array}{l}\text { Non significant } \\
(\mathbf{0 . 2 5 D t o}<\mathbf{1 D})\end{array}$ & $\begin{array}{l}\text { Significant (1D To } \\
\text { <2D) }\end{array}$ & High ( $\square$ 2 D) & 2-Value & p-value \\
\hline Pre-op & $108(54 \%)$ & $64(32 \%)$ & $28(14 \%)$ & \multirow{2}{*}{1.73} & \multirow{2}{*}{ P $<0.0001$} \\
\cline { 1 - 3 } $\mathbf{1}^{\text {st }}$ follow up & $40(20 \%)$ & $86(43 \%)$ & $74(37 \%)$ & & Significant \\
\cline { 1 - 3 } $\mathbf{2}^{\text {nd }}$ follow up & $40(20 \%)$ & $89(44.5 \%)$ & $71(35.5 \%)$ & $67(33.5 \%)$ & \\
\hline Last follow up & $50(50 \%)$ & $83(41.5 \%)$ & & \\
\hline
\end{tabular}

Graph4: Distribution of patients according to Astigmatism in Diopters

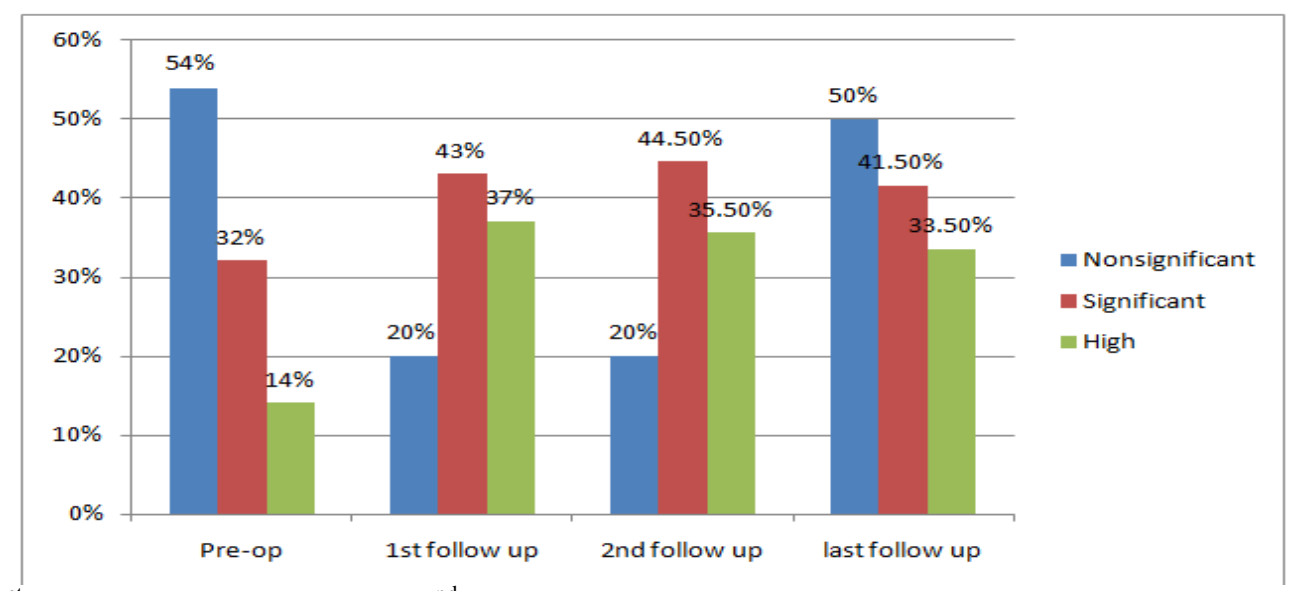

$1^{\text {st }}$ follow-up 4 weeks post op. $2^{\text {nd }}$ follow up 4 weeks post op. Last follow up 12 weeks post op. 
There were $92(46 \%)$ patients having against the rule astigmatism with mean value of $88.24 \pm 7.37,20(10 \%)$ patients having with the rule astigmatism with mean of $180 \pm 0.00$ and $88(44 \%)$ patients found to have oblique astigmatism.

Graph5: Astigmatism according to AXIS -

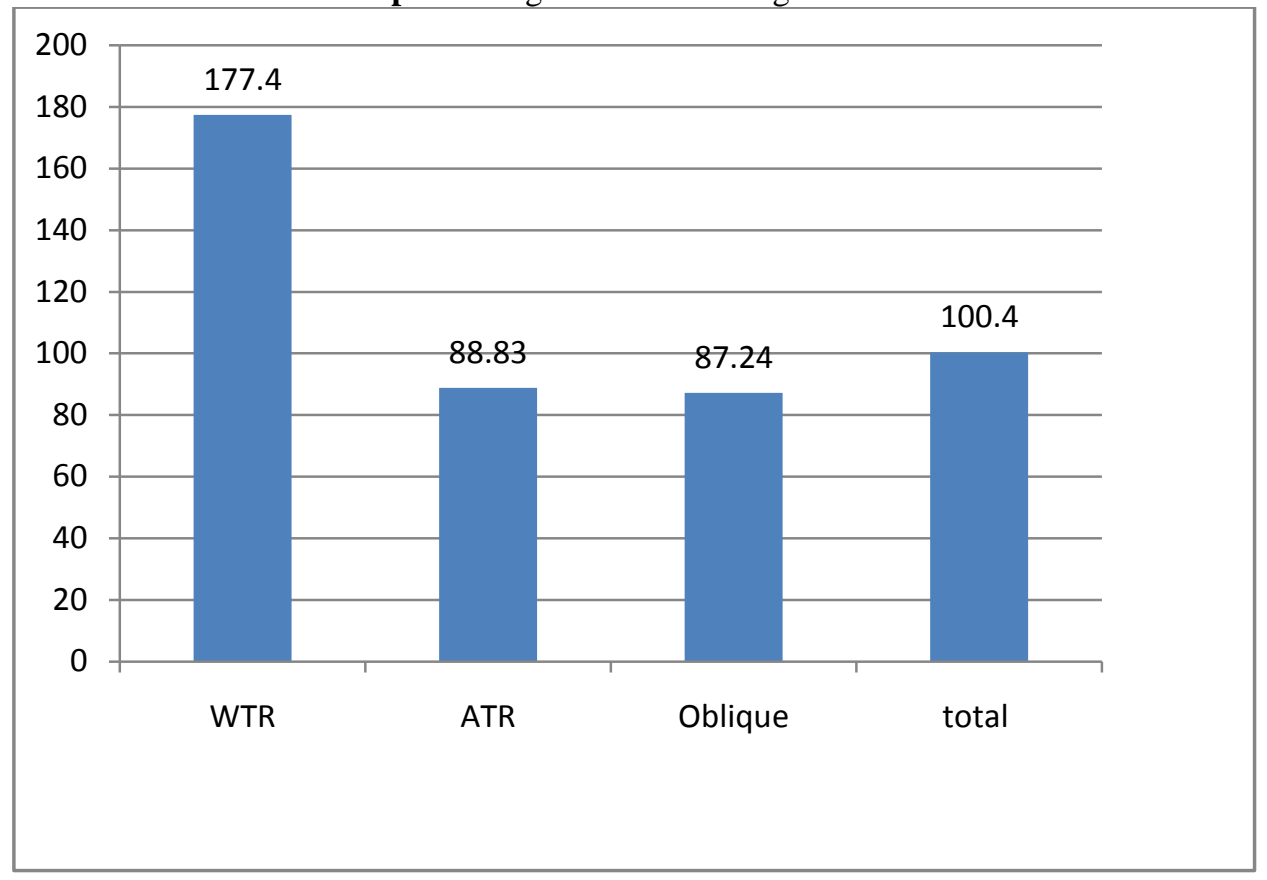

Out of 200 patients, 108(54\%) patients achieved BSCVA of 6/6 and 61 (30.5\%) patients having BSCVA of 6/9 with no patients having BSCVA $<6 / 18$.

Graph 6: Distribution of patients according to Best Spectacle Corrected Visual Acuity (BSCVA)

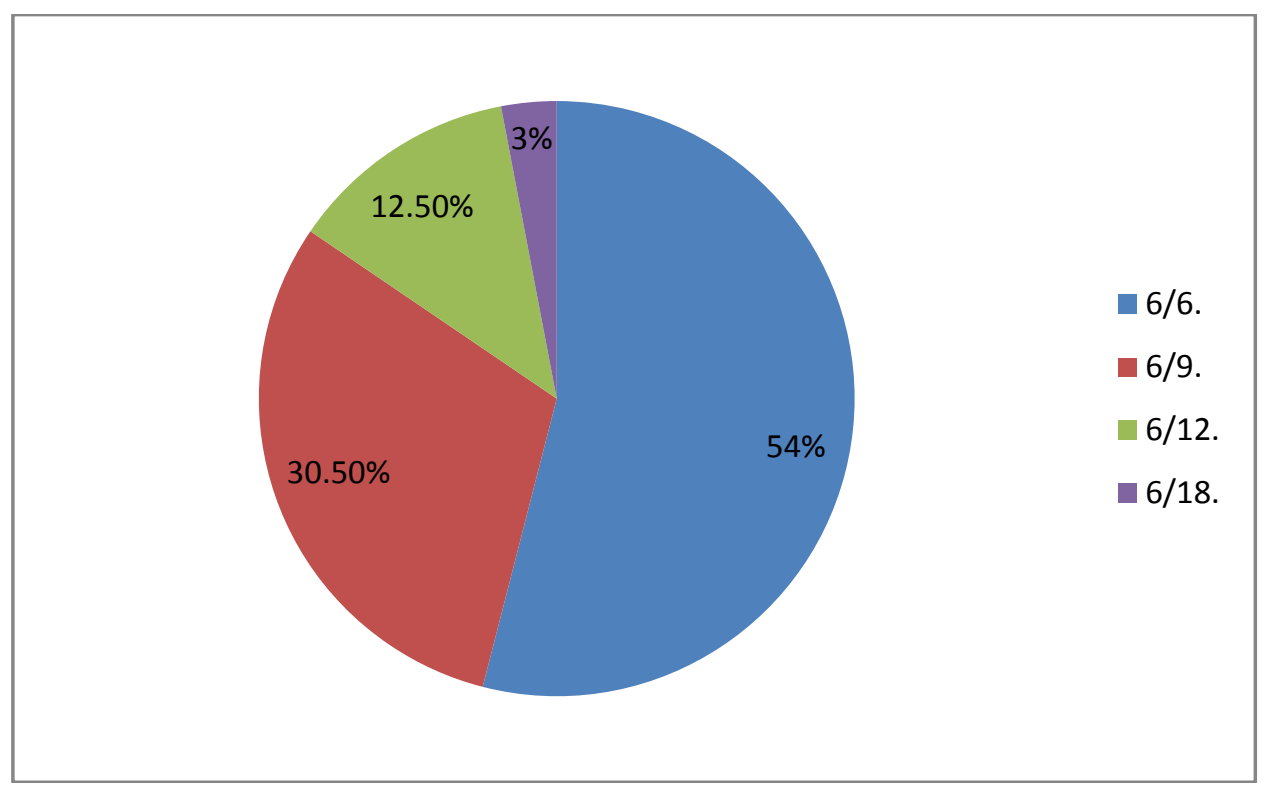

In our study $23(11.5 \%)$ patients developed Striate Keratopathy, 20(10\%) developed corneal oedema, 11(5.5\%) patients had increased IOT, $4(2 \%)$ with Desmet's Stripping and $2(1 \%)$ with wound leak. Also we found $6(3 \%)$ patients with post op anterior segment inflammation and $3(1.5 \%)$ patients with intra operative hyphema. 
Graph 7 : Distribution of patients according to complications-

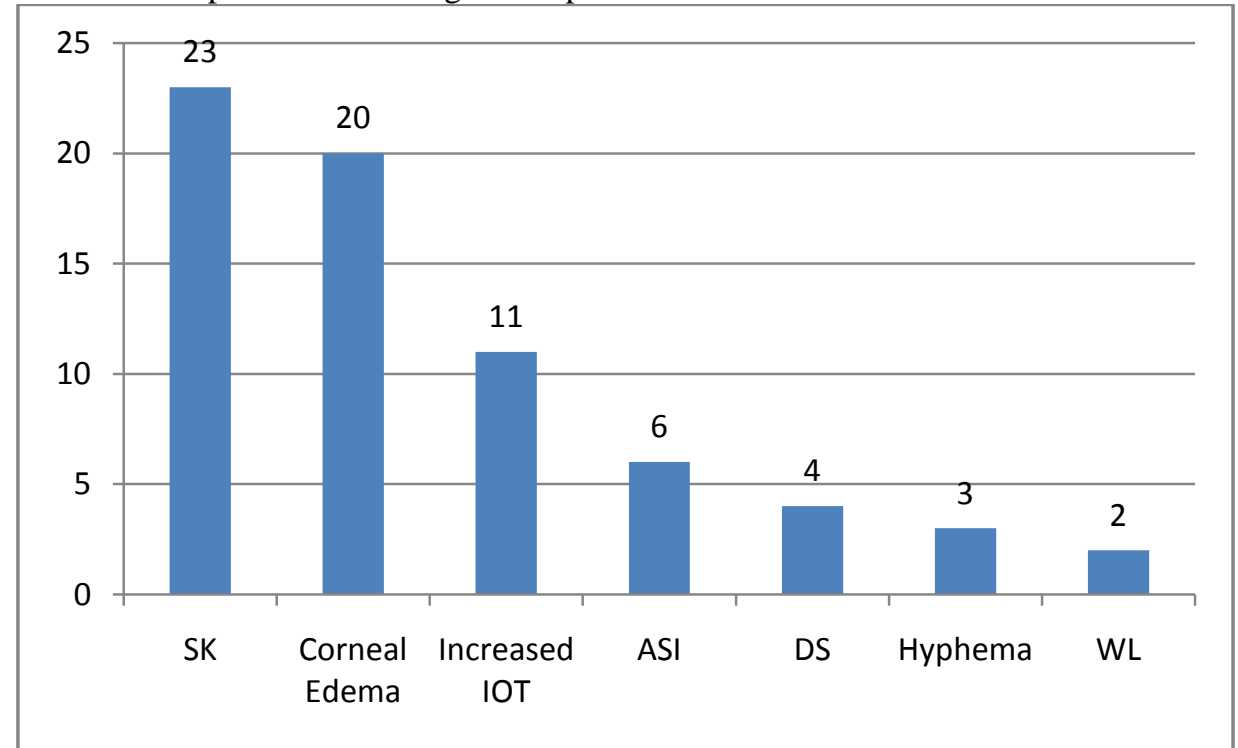

SK- Striate Keratopathy, DS-Descemet's Stripping, ASI- Post op Anterior Segment Inflamation and WLwound leak.

\section{Discussion}

In this study, we tried to assess the safety, efficacy in terms of visual recovery and induced astigmatism in eyes undergoing cataract surgery by the technique of manual sutureless small incision cataract surgery. Phacoemulsification is the universally accepted and most widely practiced technique of cataract surgery in developed countries; however, it cannot be widely adopted in developing world because of the financial and technological constraints. In this regard, manual sutureless small incision cataract surgery technique turns out to be a safe, effective, and cost-effective alternative.

Post operative CVA with pin hole was 6/12 or better in $174(87 \%)$ eyes at 1 week and $191(95.5 \%)$ eyes at 4 week and 194(97\%) of eyes at 12-weeks respectively which is higher than other studies. Out of 200 patients, 108(54\%) patients achieved BSCVA of $6 / 6$ and 61(30.5\%) patients having BSCVA of 6/9 with no patients having BSCVA less than 6/18. The average astigmatic dioptric difference was 1.05 preoperatively, 1.67 on first follow up and 1.65 on second follow up which was reduced to 1.50 on last follow-up. This values greater than previous study conducted by Huangand Tsang (0.69D), Bartovet al20 (0.54D), Zvia, Burgansky et al $(0.16 \pm 0.98 \mathrm{D})$ and Muralikrishnan et al (1.33D- vector analysis method)

Therefore hyphema did not result insignificant adverse effect and was mostly spontaneously resolved in due course of time. Anterior segment inflammation was controlled by subconjunctival injection of Wymisolone + Mydricane+ Gentamycine for 2 days and then patients were discharged

\section{Summary And Conclusion-}

Cataract is still the leading cause of avoidable blindness inthe developing world. Unless cataract surgery rates were increased, the magnitude of cataract blindness will continue to increase. The current situation mandates high- volume, high-quality cataract surgery delivered at minimal costs to the underprivileged sections of the community.

Manual sutureless small incision cataract surgery retains most of the advantages offered by phaco at aminimum cost and hence leads itself to high- volume cataract surgery. Manual small incision cataract surgery is a safe and effective technique of ECCE that can be confidently adopted. Though, surgically induced astigmatism is the main complication of this technique but it is comparable with phaco and much lower than conventionally ECCE. Almost all grades of nuclear sclerosis and all sizes of cataractous lens can be dealt with this technique. Early rehabilitation of the patients and no suture-related problems are main advantages of this technique. We advocate more widespread adaptation of this technique to reduce the global backlog of cataract blindness and encourage randomized comparative trials with long term follow-up to firmly establish manual sutureless small incision cataract surgery as a safe and effective technique for cataract surgery, especially in developing world. 


\section{References}

[1]. Resnikoff S, Pascolin D, Etya'ale D, Kocur I, Pararajasegaram R, Pokharel GP, et alGlobal data on visual impairment in

[2]. the year 2002. Bull World Health Organ 2004;82:844-51.

[3]. Foster A. VISION 2020: The cataract challenge. J Comm Eye Health 2000;13:17-9.

[4]. Ramachandra P. Importance of monitoring cataract. J Comm Eye Health 2002;15:49-50.

[5]. Spalton D, Koch D. The constant evolution of cataract. Br Med J 2000;321:1304.

[6]. Minassian DC, Rosen P, Dart JK, Reidy A, Desai P, Sidhu M, et al. Extracapsular cataract extraction compared with small incision surgery by phacoemulsification: A randomised trial. Br J Ophthalmol 2001;85:822-

[7]. FMOH. The The National Strategic Health Development (NSHDP) (2010-2015). Abuja: Federal Ministry of Health; 2010. p. 1-136.

[8]. Gogate P, Deshpande M, Nirmalan P. Why dophacoemulsification? Manual small-incision cataract surgery is almost as effective, but less expensive. Ophthalmology 2007;114:965-8.

[9]. Lecuona K, Cook C, Lansingh VC. Cataract surgery in Africa. Available from:http://www.ptolemy.ca/members/archives/2009/Cataract/index.html [Last cited on 2013 Jan 21].

[10]. Mpyet C, Dineen B, Solomon A. Cataract surgical coverage and barriers to uptake of cataract surgery in leprosy villages of north eastern Nigeria. Br J Ophthalmol 2005;89:936-8.

[11]. Rabiu MM. Cataract blindness and barriers to uptake of cataract surgery in a rural community of northern Nigeria. Br J Ophthalmol 2001;85:776-80.

[12]. Odugbo OP, Caleb DM, Muhammad RC, Aboje OA. Cataract blindness, surgical coverage, outcome, and barriers to uptake of cataract services in plateau state. Middle East Afr

[13]. J Ophthalmol 2012;19:282-8.

[14]. Gogate P, Kulkarni SR, Krishnaiah S, Deshpande RD, Joshi SA,Palimkar A,

[15]. et al. Safety and efficacy of phacoemulsification compared with manual small incision cataract surgery by a randomized control trial: Six weeks results. Ophthalmology

[16]. 2005;112:869-74.

[17]. Ruit S, Tabin G, Chang D, Bajracharya L, Kline DC, Richheimer W, et al. A prospective randomized clinical trial of phacoemulsification vs. manual sutureless small-incision

[18]. extra capsular cataract surgery in Nepal. Am J Ophthalmol 2007;43:32-8.

[19]. Gogate PM. Small incision cataract surgery: Complications and mini-review. Indian J Ophthalmol 2009;57:45-9.

[20]. Gogate P. Comparison of various techniques for cataract surgery, their efficacy, safety, and cost. Oman J Ophthalmol 2010;3:105-6.

[21]. Leaming DV. Practice styles and preferences of ASCRS members. J Cataract Refract Surg 1999;25:851-9.

[22]. Sandford-Smith J. Sutureless cataract surgery, principles and steps. J Community Eye Health 2003;6:49-53.

[23]. Henning A. Sutureless non-phaco cataract surgery. A solution to reduce cataract blindness. Community Eye Health 2003;16:49-51.

[24]. Venkatesh R, Muralikrishnan R, Civerchia BL, Karthik PS, Venkatesh P. Outcomes of high volume cataract surgeries in a developing country. Br J Ophthalmol 2005;89:1079-83.

[25]. Singh S, Winter 1, Surin L. Phacoemulsification versus small incision cataract surgery (SIC): Which one is a better surgical option for immature catarct in developing countries. Nepal J Ophthamol 2009;1:95-100.

[26]. Tabin G, Chen M, Espander L. Cataract surgery for the developing world. Curr Opin Ophthalmol 2008;19:55-9.

[27]. Ibanga A, Asana U, Ajewole J, Nkanga D, Oworu O. Outcome of cataract in southern Nigeria. S A Ophthalmol 2013;8:31-7.

[28]. Noertjojo K, Mildon D, Rollins D, Law F, Blicker J, Courtright P, et al. Cataract surgical outcome at vancourer eye centre: Can it be predicted using current data. Can J Ophthalmol 2004;39:38-47.

[29]. Cook NJ. Evaluation of high volume cataract extraction with PC-Lens implantation in Sierra Leone, West Africa. Br J Ophthalmol 1996;80:698-701.

[30]. Egbert P, Buchanan M. Results of extracapsular cataract surgery and intraocular lens implantation in Ghana. Arch Ophthalmol 1991;109:1764-8.

[31]. Nwosu SN. Prevalence and pattern of retinal disease at the Guinness Eye Hospital, Onitsha, Nigeria. Ophthalmic Epidemiol 2000;7:41-8

[32]. Adejor G. Early experience with posterior chamber intra-ocular (PC-IOL) implantation in national eye Centre, Kaduna. Nig J Ophthalmol 1997;5:6-12.

[33]. Bekibele C, Ubah J, Fasina O. A comparative evaluation of outcome of cataract surgery at Ago-Iwoye, ogun State. Nig J Surg Res 2004;6:25-9.. 